\title{
Application of Fuzzy Topsis in Selecting the Major Factor Influencing Malaysians' Choice of University (IPTA or IPTS)
}

\author{
Nur Syuhada Muhammat Pazil ${ }^{*}$, Norwaziah Mahmud², Siti Hafawati Jamaluddin ${ }^{3}$ \\ Saidatul Shareen Shakiren ${ }^{4}$ \\ ${ }^{1,2,3,4}$ Faculty of Computer \& Mathematical Sciences, Universiti Teknologi MARA Perlis Branch, \\ Malaysia \\ Corresponding author: *syuhada467@uitm.edu.my \\ Received Date: 7 August 2018 \\ Accepted Date: 17 October 2018
}

\begin{abstract}
Currently there are about 500 institutions throughout Malaysia which offer tertiary education level. They consist of public and private colleges. However, this variety will lead to confusion among the Malaysians in order to choose the right places to further their studies. The aim of this study is to select and rank the significant factor which influences the selection of university between IPTA and IPTS. By approaching the main objective, the sub-objective; to determine the most preferred university based on the associated factor can also be examined. Fuzzy TOPSIS (Fuzzy Technique for Order Preference by Similarity to Ideal Solution) is one of the best methods to assess this kind of multi-criteria decision-making problem. The alternative of this research will be the factors influencing Malaysians' choice of universities which are affiliation, course offered, cost of education and reputation. While the criteria will be IPTA and IPTS. The data was collected by interviewing experts in both fields; public and private sectors. The result referred by the value of closeness coefficient of each alternative is determined in order to rank those alternatives (factors). Based on the result, the major factor is affiliation while the rest is course offered, cost of The most preferred is IPTS that represents a better affiliation
\end{abstract}

Keywords: fuzzy topsis, institution, affiliation, course offered, education.

\section{INTRODUCTION}

There are two sectors involved in preparing tertiary or higher education level for this country which are public and private sectors. Both sectors have produced large number of universities in order to fulfill the demand of education in Malaysia. Based on Khairani and A. Razak (2013) in their article, public sector, which is controlled by the government of Malaysia, has offered about 22 universities (IPTA), 30 polytechnics and 73 public community colleges over Sabah, Sarawak and peninsular. On the other hand, the numbers of private universities (IPTS) are about 53. While the rest consist of six foreign university branch campuses and 403 active private colleges.

Normally, most students will further their studies in colleges or universities after sitting for Sijil Pelajaran Malaysia (SPM), matriculation college or Sijil Tinggi Pelajaran Malaysia (STPM) for undergraduate programs. Generally, there are numerous choices that students might have in order to further their studies whether in public or private institution. Although both industries offer the same package either for diploma or bachelor degrees, there must be a gradual differentiation in terms of quality and reputation among these institutions.

The main objective of this study is to determine the major factor, which are affiliation, course offered, cost of education and reputation that influences or will influence Malaysian choice of public or private university. The sub-objectives are to determine the most preferred university between IPTA and IPTS 
among the Malaysians and to rank the importance of four chosen factors in influencing Malaysian choice of IPTA and IPTS

The data were collected through interview process. The researcher interviewed a person who is considered an expert in the field of the topic research. The expert was given a set of questionnaire. The questionnaire involve the ranking of alternatives for the criterion based on the linguistic scale that has been chosen for this research. Hence, the expert should tick on the scale given based on their significance. Since the questionnaire has been run using linguistic variable, therefore, it must be converted into fuzzy number so that numerical decision making process could be done. The method used in this study is Fuzzy Technique for Order Preference by Similarity to Ideal Solution (TOPSIS).

The purpose of this study may help them to recognise the main factor to consider in order to choose an instituition to further their studies. Hence it may aid the decision making process of upcoming university students in choosing their study place. In addition, it can also be a reference for public and private universities themselves in order to determine their university image based on the experts' perspective. Hence, they can upgrade their quality to compete with others.

\section{RELATED WORKS}

\section{Factors Influencing Malaysian Choice of University}

Misran et al. (2012) had considered six factors that influence students in choosing university programmes which are the influence of surroundings, follow friends' selection, suitability with personality and interest, information from media, career history, cost of education and financial support. Based on the result obtained, they ranked the top three major factors are suitability with personal and interest, cost of education and information about the instituition from the media. While in Ramayah et al. (2003), students gave the highest ranking to issues such as financial, field of study, general academic reputation, location, social atmosphere, aculty teaching reputation, academic standard, and career prospect.

Affiliation or facilities is one of the fixed characteristics of a university (Ming, 2010). Some examples of educational affiliation are wi-fi, classrooms, laboratories' equipments and libraries. The efficiency of the services can also be categorised as a good facility. With the existence of good facilities, it will smoothen the learning process as well as making it convenient for the students physically and mentally. The students do not have to spend a lot of money in order to enjoy services that do not exist in the university. Hence, they can focus on their learning process only.

Normally, students who are from medium or low class income of families will consider this as one of the factors to choose their studiy place. So, in order to support the desire of the students to enter a university, there are so many financial aids offered to them such as student loans, scholarships, grants, and work-study programs (Kenayathulla \& Tengyue, 2016).

The image of the university is also important in order to determine whether the university is a good enough or not. There are so many reason to increase the reputation of university. One of them is the career history of the alumni of the university. Besides, the reputation may also be influenced and distorted by the marketing strategies of the university. Hashim and Mahmood (2011) stated that one of the government agencies that provides the accreditation of a university is Malaysian Qualification Agency (MQA). In order to get the accreditation, a standard quality should be achieved. 


\section{Application of Fuzzy TOPSIS}

Fuzzy Technique for Order Preference by Similarity to Ideal Situation (TOPSIS) is one of the methods for solving MCDM (Multi Criteria Decision Making) problem. MCDM problem is frequently encountered in practice although it is a complex, multi-objective task due to uncertain data (Mavi et al., 2016). One example of scenario of MCDM problem is a group of people who intends to determine which brand of smartphone to buy based on certain criteria. For instance the criteria are price, screen size and battery life. The alternative is the brands of the smartphone. Hence, the decision makers will give their opinion on which criteria is more significant. Different decision makers will certainly have different opinions. There are several existing methods that can be applied to solve this problem which are Fuzzy Analytic Hierarchy Process (AHP), Fuzzy Technique for Order Preference by Similarity to Ideal Solution (TOPSIS), ELECTRE, rough sets theory and multi-objective programming (Choudhary \& Shankar, 2012). These are called Multi-Criteria Decision Methods (MCDM).

\section{RESEARCH METHODOLOGY}

\section{Step1: Determination of linguistic terms, membership functions and the weightage of evaluation} criteria.

The linguistic variables for all criteria must be identified. This is because each linguistic variable will indicate a set of membership functions. Hence, determining the weightage of the evaluation criteria and the ratings of the alternatives is considered by linguistic terms. Table 1 shows the linguistic variable and corresponding triangular fuzzy numbers extracted by Chen (2000).

Table 1: Fuzzy Ratings for Linguistic Variables

\begin{tabular}{|c|c|c|c|c|c|}
\hline $\begin{array}{c}\text { Linguistic } \\
\text { Variable }\end{array}$ & $\begin{array}{c}\text { Equally } \\
\text { Important }\end{array}$ & $\begin{array}{c}\text { Weakly } \\
\text { Important }\end{array}$ & $\begin{array}{c}\text { Strongly } \\
\text { Important }\end{array}$ & $\begin{array}{c}\text { Very Strongtly } \\
\text { Important }\end{array}$ & $\begin{array}{c}\text { Extremely } \\
\text { Important }\end{array}$ \\
\hline Fuzzy Value & $(0,1,3)$ & $(1,3,5)$ & $(3,5,7)$ & $(5,7,9)$ & $(7,9,9)$ \\
\hline
\end{tabular}

\section{Step 2 : Construct the fuzzy decision matrix}

The decision matrix is directly associated with the linguistic variables and the criteria alternatives. Assume that $n$ is the number of criteria and $m$ is the number of alternatives. Therefore, the fuzzy decision matrix will be obtained with $m$ rows and $n$ columns as in the following matrix:

$$
\widetilde{D}=A_{2}\left[\begin{array}{lll}
x_{11} & x_{12} & x_{13} \\
x_{21} & x_{22} & x_{23} \\
x_{31} & x_{32} & x_{33}
\end{array}\right]
$$

By rows $A_{1}, A_{2}, \ldots, A_{m}$ are alternatives which are referred to the factors that influence Malaysians' choice of public or private university. While by columns, $C_{1}, C_{2}, \ldots, C_{m}$ are referred to the criteria that have been considered in order to rate the alternatives.

\section{Step 3: Aggregate the weightage of the criteria and alternatives}

Assume that decision makers are equal to $k$ th. If the fuzzy rating and importance weight of the $k$ th decision maker, have the $i$ th alternative and $j$ th criteria, therefore the equation of weight of alternative and criteria are as follows respectively:

$$
\begin{aligned}
& \tilde{x}_{i j}=\left(a_{i j}, b_{i j}, c_{i j}\right) \\
& \widetilde{w}_{i j}=\left(x_{i j}, y_{i j}, z_{i j}\right)
\end{aligned}
$$




\section{Step 4 : Normalize the fuzzy decision matrix}

Normalization of fuzzy decision matrix is accomplished using linear scale transformation. The calculation is as follows:

$$
\begin{aligned}
& \widetilde{r}_{i j}=\left(\frac{a_{i j}}{c_{j}}, \frac{b_{i j}}{c_{j}}, \frac{c_{i j}}{c_{j}}\right) \text { and } c_{j}^{+}=\max c_{i j} \text { (benefit) } \\
& \widetilde{r}_{i j}=\left(\frac{a_{j}^{-}}{c_{i j}}, \frac{a_{j}^{-}}{b_{i j}}, \frac{a_{j}^{-}}{a_{i j}}\right) \text { and } a_{j}^{-}=\min a_{i j} \text { (cost) }
\end{aligned}
$$

If in the factors that influence Malaysians' choice of public or private university criteria indicates the benefit, use formula in Eqn. (1.4). Otherwise, for the criteria which represent the cost in normalization of matrix formula in Eqn. (1.5) is used. In the quality evaluation the cost benefit criteria will be used. The normalized fuzzy decision matrix can be represented by equation 1.6:

$\widetilde{R}=\left[\widetilde{r}_{i j}\right]_{m \times n}, i=1,2, \ldots m ; j=1,2, \ldots J$

where $\mathrm{r}_{\mathrm{ij}}$ is the normalized value of $x_{i j}=\left(a_{i j}, b_{i j}, c_{i j}\right)$.

\section{Step 5 : Calculate the weighted normalized fuzzy decision matrix}

The weighted normalized fuzzy decision matrix $\mathrm{V}$ is computed by multiplying the weights, $w_{i j}$ of evaluation criteria with the normalized value $r_{i j}$ from fuzzy decision matrix. The weighted normalized decision matrix can be represented by equation 1.7 :

$\widetilde{V}=\left[\widetilde{v}_{i j}\right]_{n \times j}, i=1,2, \ldots n ; j=1,2, \ldots, n$

Where

$\widetilde{v}_{i j}=\widetilde{r}_{i j}(.) \widetilde{w}_{i}$

\section{Step 6 : Determine the Fuzzy Positive-Ideal Solution (FPIS $A^{+}$) and Fuzzy Negative-Ideal Solution}

(FNIS $A^{-}$)

According to the weighted normalized fuzzy decision matrix, in this step determine the positive and negative displacement from the ideal solution. Their ranges belong to the closed interval $[0,1]$. FPIS and FNIS are defined as triplet $(1,1,1)$ or $(0,0,0)$, otherwise the values determined by using the following formula:

$$
\begin{aligned}
& A^{*}=\left(v_{1}, v_{2}, \ldots, v_{n}\right), \widetilde{v}=\max \left\{v_{i j}\right\} \\
& A^{-}=\left(v_{1}, v_{2}, \ldots, v_{n}\right), \widetilde{v}=\min \left\{v_{i j}\right\}
\end{aligned}
$$

Step 7 : Calculate the distance of each alternative from FPIS and FNIS

In order to calculate the distance between two triangular fuzzy numbers, the formula used is as follows:

$$
d_{v}(a, b)=\sqrt{\frac{1}{3}\left[\left(a_{1}-b_{1}\right)^{2}+\left(a_{2}-b_{2}\right)^{2}+\left(a_{3}-b_{3}\right)^{2}\right]}
$$

However, to find the distance of each alternative from FPIS, $\left(b_{1}, b_{2}, b_{3}\right)$ must be equal to $(1,1,1)$ while FNIS must be equal to $(0,0,0)$. 


$$
\begin{aligned}
& d_{i}^{+}=\sqrt{\frac{1}{3}\left[\left(\widetilde{v}_{1}-1\right)^{2}+\left(\widetilde{v}_{2}-1\right)^{2}+\left(\widetilde{v}_{3}-b\right)^{2}\right]} \\
& d_{i}^{-}=\sqrt{\frac{1}{3}\left[\left(\widetilde{v}_{1}-0\right)^{2}+\left(\widetilde{v}_{2}-0\right)^{2}+\left(\widetilde{v}_{3}-0\right)^{2}\right]}
\end{aligned}
$$

Where $\left(a_{1}, a_{2}, a_{3}\right)$ is the value of Fuzzy Positive Ideal Solution (FPIS) of the alternatives and Fuzzy Negative Ideal Solution (FNIS) of the alternatives.

\section{Step 8 : Calculate the closeness coefficient}

The closeness coefficient $\mathrm{CCi}$ is defined to determine the ranking order of all alternatives. The index $\mathrm{CCi}$ indicates that the alternative is close to the FPIS $\left(d^{+}\right)$and far from the FNIS $\left(d^{-}\right)$. The closeness coefficient of each evaluated teacher quality can be calculated as:

$$
C C_{i}=\frac{d_{i}^{+}}{d_{i}^{+}+d_{i}^{-}}
$$

\section{Step 9: Rank the order of all alternatives.}

The ranking of alternatives is carried out based on the calculated closeness coefficients. The alternative with the highest coefficient represents the best alternative.

\section{RESULT AND DISCUSSION}

The alternatives (affiliation, cost of education, course offered and reputation) and criteria (IPTA and IPTS) were rated by their importance or significance by referring to the linguistics rating variables as shown in Table 1. Table 2 shows the results after transferring the linguistic scale into Fuzzy number.

Table 2: Significance Of Criteria Based on Fuzzy Number

\begin{tabular}{|c|c|c|c|c|}
\hline & Affiliation & Cost of Education & Course Offered & Reputation \\
\hline IPTA & $(5,7,9)$ & $(3,5,7)$ & $(3,5,7)$ & $(5,7,9)$ \\
\hline IPTS & $(7,9,9)$ & $(7,9,9)$ & $(7,9,9)$ & $(5,7,9)$ \\
\hline
\end{tabular}

The decision matrix is later created according to the above information. The decision matrix is actually the average of experts' opinions about the alternatives in each criteria. However, since the number of expert in this study is one, hence the value of each alternative in the decision matrix remains the same. On the other hand, the weight of each alternative and criterion should be calculated. The fuzzy decision matrix is used to find the weight. Normalization of data is needed to store each row of data only once in order to avoid data anomalies. Fuzzy decision matrix is normalized into two ways, benefit criteria and cost criteria .By using the value of weighted and normalization aggregated fuzzy decision matrix for benefit and cost criteria, the weighted normalized aggregation fuzzy decision matrix was obtained. The Eq. (1.9) and (1.10) are used to find Fuzzy Positive Ideal Solution (FPIS) and Fuzzy Negative Ideal Solution (FNIS). Hence, after getting the value of FPIS and FNIS, the distance of each alternative from FPIS and FNIS were calculated to determine the positive and negative displacement from the ideal solution. Last but not least is ranking the order of all four factors. This technique allows or will allow the decision maker to choose the most feasible alternative.

According to the Table 3, the ranking order of these four alternatives is affiliation, reputation, course offered and cost of education respectively. If the distance of factor closer to FPIS, then it will be the first one in the 
ranking. On the other hand, if the alternative is the nearest from FNIS, it will also be the last one in the rank.

Table 3: Fuzzy TOPSIS Result

\begin{tabular}{|l|c|c|c|c|}
\hline & $\begin{array}{c}\text { Positive } \\
\text { Displacement, } \\
\mathrm{d}+\end{array}$ & $\begin{array}{c}\text { Negative } \\
\text { Displacement, } \\
\mathrm{d}-\end{array}$ & $\begin{array}{c}\text { Closeness } \\
\text { Coefficient, } \\
d_{i}^{+}\end{array}$ & $\begin{array}{c}\text { Ranking the } \\
\text { Alternative }\end{array}$ \\
\hline Affiliation & 19.68 & 6.73 & 0.75 & 1 \\
\hline $\begin{array}{l}\text { Cost of } \\
\text { Education }\end{array}$ & 19.68 & 9.13 & 0.68 & 3 \\
\hline $\begin{array}{l}\text { Course } \\
\text { offered }\end{array}$ & 19.68 & 9.13 & 0.68 & 3 \\
\hline Reputation & 15.43 & 6.73 & 0.70 & 2 \\
\hline
\end{tabular}

\section{CONCLUSION AND RECOMMENDATION}

According to the results, the major objective of this research was achievable. According to the value of closeness coefficient of the alternatives (four factors), it was seen that affiliation had the highest coefficient value which is 0.75 and ranked as the first. Therefore, the affiliation of university is recommended as the main factor that should be considered in choosing university. Hence, based on the decision maker's opinion, the institution that is most preferred is IPTS that represents a better affiliation. The last objective of this research is to rank the four factors by their importance. The factor that was ranked as the second important is the reputation of the university. The value of closeness coefficient is 0.70 . While the third place is shared by two factors that have similar weightage in choosing a university. The factors are cost of education and course offered. Thus, the ranking was successfully made after taking into account the multiple criteria.

In future, it is recommended that the researcher to try for more experts to get more precise criteria. The researcher can try other multi-criteria techniques in MCDM like Fuzzy AHP, ELECTRE, rough sets theory and multi-objective programming to confirm the objective of this study. Besides, they can also add more alternatives (factors) in consideration. Furthermore, Fuzzy TOPSIS can also be applied in other cases of study in order to solve multi-criteria decision-making problem.

\section{REFERENCES}

Chen, C. T. (2000). A fuzzy approach for supplier evaluation and selection in supply chain management. International Journal of Production Economics, 102, 289-301.

Choudhary, D., \& Shankar, R. (2012 An STEEP-fuzzy AHP-TOPSIS framework for evaluation and selection of thermal power plant location : A case study from India, Energy, 655-671.

Hashim, R., \& Mahmood, R. (2011). Comparing commitment to service quality among academic staffs in private and public Malaysian universities, Journal of International Management Studies, 6.1, 1-8.

Kenayathulla, H. B. \& Tengyue, Z. (2016). Student loans in Malaysia and China: Equity, efficiency and adequacy. Malaysian Online Journal of Educational Management, 4(1), 64-85. 
Khairani, A. Z., \& Razak, A. N. (2013). Assessing Factors Influencing Students' Choice of Malaysian Public University: A Rasch Model Analysis, International Journal of Applied Psychology, 3(1), 1924.

Mavi, R. K., Goh, M., \& Mavi, N. K. (2016). Supplier selection with Shannon entropy and fuzzy TOPSIS in the context of supply chain risk management. Procedia - Social and Behavioral Sciences, 235, 216 $-225$

Ming, J. S. K. (2010). Institutional factors influencing students' college choice decision in Malaysia : A Conceptual Framework. International Journal of Business and Social Science, 1(3), 53-58.

Misran, N., Sahuri, S., Arsad, N., Hussain, H., Zaki, W. M. D., \& Aziz, N. A. (2012). The influence of socio-economic status among matriculation students in selecting university and undergraduate program, International Conference on Teaching and Learning in Higher Education (ICTLHE 2012) in conjunction with RCEE \& RHED 2012, 56, 134-140.

Ramayah, T., Nasurdin, M. A., Noor, M., \& Hassan, H. (2003). Students' Choice Intention of a Higher Learning Institution: An Application of the Theory of Reasoned Action (TRA), Malaysian Management Journal, 7(1), 47-62. 